\title{
Pembelajaran Omotenashi Bagi Pramuwisata Travel Standard Japan
}

\author{
${ }^{1}$ A.A.Ayu Dian Andriyani \& ${ }^{2}$ Ni Wayan Meidariani \\ Fakultas Bahasa Asing Universitas Mahasaraswati Denpasar ${ }^{1,2}$ \\ Email: agungdianstiba@gmail.com, meidariani@hotmail.com
}

\begin{abstract}
ABSTRAK
Pulau Bali merupakan destinasi wisata baik lokal maupun mancanegara. Guna meningkatkan jumlah kunjungan wisatawan salah satunya Jepang, Bali membutuhkan pramuwisata yang profesional dalam memberi pelayanan kepada wisatawan. Pramuwisata tidak saja harus memahami budaya lokal tetapi juga harus mengerti tentang budaya wisatawan yang dilayani. Apabila terjadi kesalahpahaman akibat kurangnya pemahaman budaya khususnya dalam hal pelayanan atau disebut omotenashi ketika berinteraksi dengan wisatawan Jepang akan berdampak pada kualitas pelayanan yang diberikan. Pramuwisata sangat membutuhkan pengetahuan lebih tentang tata cara memberikan pelayanan jasa kepada konsumen karena Jepang memiliki tata cara pelayanan yang berbeda dengan Indonesia. Oleh karena itu Program Studi Sastra Jepang Fakultas Bahasa Asing Universitas Mahasaraswati Denpasar turut serta bertanggung jawab membantu meningkatkan kualitas pelayanan menurut budaya Jepang dengan memberikan pelatihan omotenashi Jepang yang selama ini selalu menjadi kendala saat berinteraksi. Pelatihan dalam memahami omotenashi Jepang menggunakan metode pembelajaran student centered didukung pendekatan communicative language teaching dengan dasar pertimbangan bahwa menggunakan metode ini mampu memberikan suasana belajar lebih komunikatif dalam memahami omotenashi bagi peningkatan pelayanan berbahasa pramuwisata saat memberikan pelayanan jasa kepada wisatawan Jepang menurut budaya Jepang, karena dalam pelatihan peserta diharapkan mampu mempraktekkan teori yang telah didapat dengan peserta lainnya. Hasil pelatihan omotenashi ini diharapkan dapat meningkatkan kualitas pelayanan saat peserta berinteraksi dengan wisatawan.
\end{abstract}

Kata kunci : pramuwisata, omotenashi, wisatawan Jepang

\section{ABSTRACT}

Bali is an interesting tourist destination both local and foreign. In order to increase the number of tourists visiting Bali, one of them is Japanese, Bali needs professional guides in providing services to japanese tourists. Tour guides must not only understand the local culture but also must understand regarding the culture of the tourists served. If there is a misunderstanding due to lack of understanding of culture, especially in giving services also called omotenashi when interacting with Japanese tourists will have an impact on the quality of services provided. Tour guides really need more knowledge regarding the procedures for providing services to consumers because Japanese has different service procedures for Indonesia. Therefore, the Japanese Literature Study Program at the Faculty of Foreign Languages is responsible for helping to improve the quality of services according to Japanese 
WIDYABHAKTI

JURNAL ILMIAH POPULER 2(3): 7-12

culture by providing Japanese omotenashi training which has been an obstacle when interacting. The training using student centered learning methods supported by communicative language teaching approaches. This is supported by the basic consideration that using this method can provide more communicative learning atmosphere in understanding omotenashi. The theory is applied with the aim to improve the language skills of guides to provide services according to Japanese culture.

Key words: Keywords: tour guides, omotenashi, Japanese tourists

\section{PENDAHULUAN}

Bali merupakan daerah pariwisata dengan keindahan pantai, sungai, gunung maupun hamparan laut yang luas serta beraneka ragam budaya yang sangat menarik. Banyak wisatawan berkunjung ke Bali untuk melihat tidak saja keindahan alam namun budaya yang dimiliki masyarakat Bali sangat beragam. Pariwisata Bali memiliki ciri khas dibandingkan destinasi pariwisata didaerah lain karena Bali merupakan pariwisata budaya yang berlandaskan ajaran Tri Hita Karana (Parma, 2010). Untuk memberikan pelayanan jasa yang baik maka peran pramuwisata sebagai pelaku terdepan sangat penting. Dinas Pariwisata bekerjasama dengan HPI Bali sebagai garda depan dalam membina para pramuwisata di Bali agar tetap menjaga kualitas pelayanan pramuwisata baik dalam pemahaman budaya lokal, kemampuan berbahasa Jepang. Namun meskipun demikian berdasarkan survei lapangan masih saja ada pramuwisata yang kurang memahami dengan baik tata cara pelayanan atau sering disebut dengan hospitality (dalam bahasa Jepang disebut omotenashi). Omotenashi merupakan hospitality khas Jepang. Pada domain pariwisata yang terpenting adalah pelayanan jasa, omotenashi merupakan senjata utama yang patut diperhitungkan. Pelayanan juga meliputi Keramahtamahan sehingga di Jepang memiliki standar dan gaya sendiri (Andriyani\& Anisa, 2019).

Berbagai jenis pengabdian masyarakat telah banyak dilakukan oleh institusi sebagai bentuk penerapan Tri Darma Perguruan Tinggi di antaranya, pengabdian melalui pemberdayaan masyarakat dan pengembangan potensi di desa Gianyar kegiatan pendampingan yang dilakukan melalui program KKN yang menghasilkan peningkatan produktivitas mitra, mutu kesehatan dan pendidikan dan pengembangan seni budaya menuju pariwisata (Dewi, Krisna Luh Gede; Penindra 2020), kegiatan pengabdian untuk meningkatkan kemampuan berbahasa Jepang juga telah dilakukan oleh beberapa institusi melalui pelatihan dalam meningkatkan pengetahuan generasi muda tentang bahasa Jepang khususnya bagi para guide (Rakian, 2018), pelatihan bahasa asing khususnya bahasa Jepang yang menekankan pada komunikasi sehari- hari. Metode pembelajaran yang digunakan berbasis paradigma student centered dengan pendekatan communicative language teaching. Tujuannya untuk meningkatkan kompetensi komunikasi bahasa Jepang dengan cara mengenalkan suatu konteks yang relevan di banjar Panca Bhineka, Tanjung Benoa, Kuta Selatan, Badung (Darlina, Lien; Solohin, 2019). Pengabdian dalam bentuk pengenalan bahasa dan budaya Jepang bagi guru serta siswa dengan tujuan agar para guru dan siswa menguasai empat kemampuan berbahasa Jepang (Kartika, Diana; Astuti, Yuni; Bakar, Yusrizal; Mardius 2017). Berbeda dengan pengabdian yang telah dilakukan oleh (Lensun 2019) dalam pengabdiannya melakukan pelatihan dalam membuat model pembelajaran bagi 
guru-guru bahasa Jepang di Manado. Semua hasil pengabdian tersebut sangat bermanfaat dan memberikan kontribusi dalam peningkatan kualitas berbahasa Jepang di Indonesia. namun umumnya belum dilakukan pengabdian bagi satu lembaga msialnya biro perjalanan. Pengabdian yang dilakukan oleh Program Studi Sastra Jepang Fakultas Bahasa Asing Universitas Mahasaraswati Denpasar melakukan pelatihan dengan tema 'Pembelajaran Omotenashi Dalam Meningkatkan Pelayanan Berbahasa Jepang Bagi Pramuwisata di Travel Standard Jepang. Biro perjalanan Jepang yang baru berdiri ini menjual berbagai paket perjalanan ke berbagai obyek wisata yang ada di Bali. Setiap biro perjalanan tentu saja memiliki standar mutu dalam memberikan pelayanan salah satunya adalah bentuk pelayanan berdasarkan budaya Jepang. Menurut observasi yang telah dilakukan, dalam kenyataannya fenomena yang terjadi saat pramuwisata memberikan pelayanan jasa ketika menemani wisatawan jepang untuk pergi ke obyek wisata banyak ditemukan kendala salah satunya pramuwisata tidak memahami dengan baik bentuk omotenashi menurut budaya Jepang.

Pengabdian dengan bentuk pelatihan guna meningkatkan kualitas omotenashi bagi pramuwisata berbahasa Jepang di salah satu biro perjalanan Jepang yang baru berdiri di Bali merupakan satu bentuk sumbangsih lembaga untuk menghindari kesalahpahaman yang berdampak pada komplin. Permasalahan ini menjadi kendala terbesar yang harus dicarikan solusi. Selain dinas pariwisata propinsi Bali bekerja sama dengan HPI Bali dalam memberikan penyuluhan terkait pelayanan berbahasa Jepang namun dirasa masih perlu dilakukan secara spesifik terkait tema omotenashi Jepang. Berdasarkan masalah tersebut di atas maka peran perguruan tinggi khususnya Fakultas Bahasa Asing Program Studi Sastra Jepang ikut berperan aktif dalam membantu meningkatkan kualitas omotenashi terhadap wisatawan jepang melalui program pengabdian masyarakat dengan harapan melalui pengabdian yang diberikan mampu memberikan pengetahuan serta pengalaman yang lebih baik agar pramuwistaa dapat meningkatkan kualitas pelayanan kepada wisatawan Jepang menurut budaya Jepang sehingga terhindar dari kesalahpahaman dalam berkomuniaksi maupun bersikat yang sangat berdampak erhadap kunjungan wisatawan Jepang.

\section{RUMUSAN MASALAH}

Fenomena yang terjadi saat pramuwisata memberikan pelayanan berbahasa terhadap wisatawan Jepang sering terjadi kesalahan dalam memberikan tanggapan, maupun sikap ketika berinteraksi dengan wisatawan Jepang serta gaya berpikir yang berbeda disebabkan oleh perbedaan budaya. Kurangnya kualitas pelayanan terhadap wisatawan Jepang menjadi hambatan tersediri bagi pramuwisata untuk berkomunikasi lebih banyak karena rasa takut yang dialaminya.

\section{METODE}

Metode yang digunakan dalam meningkatkan kualitas pelayanan dari pramuwisata menurut budaya Jepang menggunakan pembelajaran student centered learning dengan pendekatan secara komunikatif atau disebut communicative language teaching. Adapun dasar pertimbangan pemilihan pendekatan ini adalah agar situasi belajar mengajar menjadi lebih komunikatif dan suasa belajar lebih menyenangkan. Materi yang dipresentasikan adalah omotenashi Jepang yang identik dengan strategi berinteraksi, perbedaan budaya dan sikap ketika berkomunikasi dengan wisatawan Jepang. 


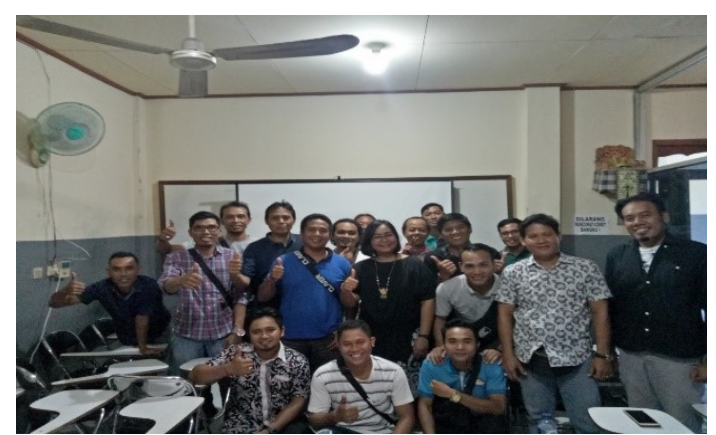

Gambar 1 Koleksi Pribadi, Pemateri berfoto bersama dengan para Pramuwisata Berbahasa Jepang

Seperti tampak pada Gambar 1, peserta pelatihan terdiri dari para pramuwisata berbahasa Jepang berjumlah 20 orang. Kegiatan dilakukan di ruang pertemuan milik biro perjalanan sehingga suasana sangat nyaman dan aman. Pemateri memberikan pelatihan selama dua hari berdasarkan pada tujuan penelitian.

\section{PEMBAHASAN}

Bentuk pengabdian masyarakat yang dilakukan oleh Program Studi Sastra Jepang salah satunya adalah melaksanakan pelatihan peningkatan omotenashi Jepang bagi pramuwisata. Kegiatan pelatihan ini diikuti oleh 20 orang pramuwisata. Kegiatan pelatihan Bahasa Jepang dilakukan selama dua hari yaitu, pada hari Senin dan Selasa pada tanggal 23 sampai dengan 24 Desember 2020. Pelatihan dilaksanakan di ruang pertemuan milik Travel Standard Japan yang berlokasi di Jalan Batuyang Tohpati Denpasar-Bali. Kegiatan pelatihan dipandu oleh tiga (3) orang dosen di lingkungan Fakultas Bahasa Asing Program Studi Sastra Jepang Universitas Mahasaraswati dengan kepakaran yang dimiliki yaitu, Linguistik dan Budaya Jepang. Materi ajar yang diberikan dikemas dalam bentuk PPT dengan tampilan Slide yang menarik karena didukung oleh video serta gambar. Metode pelatihan memberikan suasana yang cukup menarik karena dilakukan secara langsung dan komunikatif. artinya pemateri sambil memberikan teori para peserta pelatihan juga diberi kesempatan untuk pertanyaan apapun terutama yang berkaitan dengan omotenashi Jepang. Peserta juga diminta untuk mempraktekkan teori yang telah diberikan dengan teknik bermain peran seolah-olah dalam situasi tour saat pramuwisata memberikan pelayanan jasa terhadap wisatawan Jepang. Selain itu, peserta dapat mempraktekkan langsung tata cara ojigi, serta bersikap saat memberikan pelayanan jasa ketika pergi ke obyek wisata. Pelatihan dilakukan selama durasi 2 jam dalam sehari, tanpa mengurangi tujuan dari pengabdian untuk peningkatan omotenashi Jepang bagi pramuwisata terhadap wisatawan Jepang. Adapun prosedur yang dilakukan sebelum mengadakan pelatihan di antaranya adalah: 1) mengobservasi permasalahan pramuwisata tentang omotenashi Jepang, 2) mempersiapkan bahan pelatihan disesuaikan dengan tujuan pengabdian, 3) membuat bahan presentasi serta modul pelatihan 4) jika sudah siap dosen secara bergantian melakukan pelatihan omotenashi Jepang. Adapun kegiatan pada hari pertama yaitu, dosen sebagai pemateri memberikan teori tentang standar pelayanaan dalam domain pariwisata secara umum dan omotenashi menurut kajian Jepang. Pemateri dan peserta melakukan diskusi dengan baik dan mempraktekkan tata cara pelayanan menurut standar omotenashi Jepang seperti memberikan senyum, maupun merespon tuturan wisatawan Jepang. Pada hari kedua pemateri memberikan pelatihan tata cara menghormat ala Jepang 'Ojigi', tata cara bertukar kartu nama, tatacara mengemudi yang baik dan sopan santun menurut budaya Jepang. 


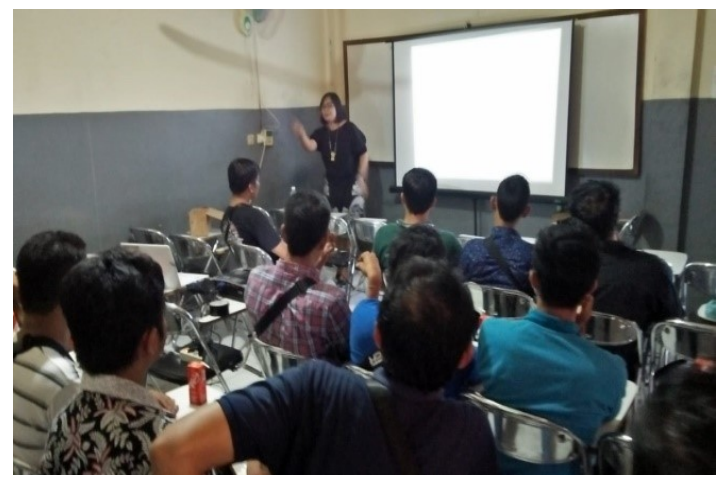

Gambar 2 Koleksi Pribadi. Dosen selaku pemateri sedang memberikan pelatihan tentang omotenashi Jepang

Evaluasi pembelajaran dilakukan dengan memberikan kuesioner kepada peserta seusai pelatihan. Hal ini dilakukan untuk mengetahui kebermanfaat pelatihan. Kuesioner dianalisis untuk mencari prosentasi butir dalam pertanyaan. Berdasarkan hasil evaluasi dapat diketahui bahwa 1) seluruh peserta menyatakan bahwa pelatihan omotenashi ini sangat penting dan bemanfaat yaitu pada prosentase $100 \%$, 2) $90 \%$ mengungkapkan bahwa melalui pelatihan ini ada hal baru yang mereka dapatkan. Hal ini terlihat pada grafik, Gambar 3, berikut ini.

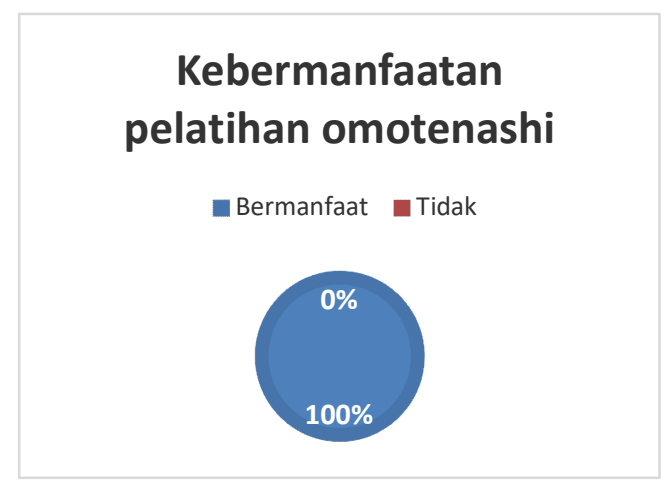

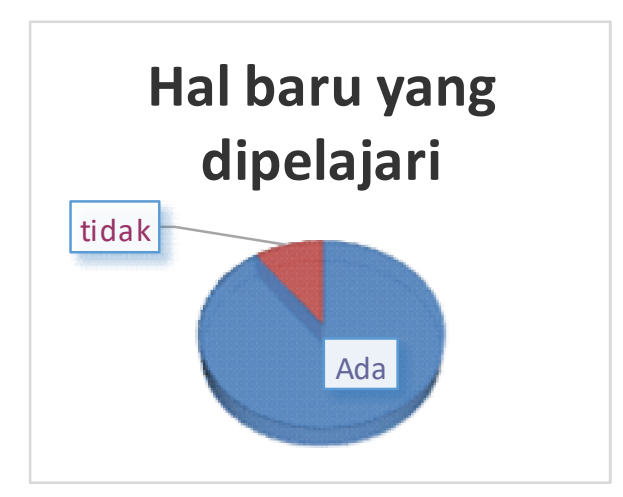

Gambar 3 Grafik tingkat kebermanfatan kegiatan Pengabdian Masyarakat.

Hasil pelatihan juga menunjukkan bahwa para peserta banyak yang sering mengalami kendala saat melayani wisatawan Jepang seperti kurang paham tentang perbedaan budaya Jepang, keterbatasan kemampuan bahasa Jepang, kurang mengenal karakter tamu jepang, dan etika berbicara dengan tamu yang usianya lebih tua. Permasalahan-permasalahan tersebut dapat dipahami setelah melaksanakan pelatihan. Para peserta pelatihan menjadi paham tentang etika memberikan pelayanan wisatawan Jepang, memahami perbedaan budaya antara budaya Jepang dan Bali dalam pergaulan selama melayani wisatawan Jepang dan yang paling penting memahami konsep omotenashi dalam melayani wisatawan Jepang.

\section{SIMPULAN}

Pelatihan yang telah diberikan mampu memberikan pemahaman yang baik tentang omotenashi Jepang. Metode student centered learning dengan pendekatan komunikatif dapat memberikan suasana berdiskusi berjalan dengan baik dan menyenangkan. Dengan pemahaman yang telah dimiliki oleh para pramuwisata maka diharapkan pramuwisata mampu membedakan dan mengkolaborasikan budaya lokal dengan Jepang guna memberikan kualitas maksimal dalam pelayanan kepada wisatawan Jepang berdasarkan standar omotenashi Jepang 


\section{UCAPAN TERIMA KASIH}

Ucapan terima kasih kami sampaikan kepada Fakultas Bahasa Asing Universitas Mahasaraswati Denpasar yang memberikan dukungan penuh bagi dosen untuk melakukan pengabdian mandiri di masyarakat, manajemen Travel Standard Japan dan seluruh peserta pelatihan yang tergabung dalam pramuwisata di Travel Standard Japan. Terima kasih atas peran serta selama pelaksanaan pelatihan.

\section{DAFTAR PUSTAKA}

Andriyani, Dian A.A.Ayu \& Atiqah, Annisa Nurul. 2018. Bahasa Jepang Bisnis 'Tingkat Tutur Bahasa Jepang Untuk Pelaku Industri Pariwisata". Yogyakarta:Erhaka Utama.

Darlina, Lien; Solohin. 2019. "Peningkatan Kapasitas Bahasa Jepang Dasar Dan Etika." Widyabhakti Jurnal Ilmiah Populer 2(1): 7-12.

Dewi, Krisna Luh Gede; Penindra, Budiana Dwi I Made. 2020. "Pemberdayaan Masyarakat Dan Pengembangan Potensi Wilayah Di Desa Manukaya Gianyar Bali." Widya 2(2): 20-29.

Kartika, Diana; Astuti, Yuni; Bakar, Yusrizal; Mardius, Ali. 2017. "Pengenalan Bahasa Dan Budaya Jepang Bagi Guru Introduction Of Japanese Language And Culture For Teachers." Jurnal Pengabdian dan Pemberdayaan Masyarakat 1(2): 16165.

Lensun, Ferro Sherly. 2019. "Pelatihan Model Pembelajaran Bagi GuruGuru." Abdimas 12(1): 13-22.

Parma, I Putu Gede. 2010. "Pengamalan Konsep Tri Hita Karana Di Hotel: Sebuah Studi Kasus Pengembangan Hotel Berwawasan Budaya Di Matahari
Beach Resort And Spa." Media Bina Ilmiah Lembaga Pengembangan Sumber Daya Insani 4(2): 1-8.

Rakian, Sandra. 2018. "Pelatihan Percakapan Bahasa Jepang Praktis Bagi Generasi Muda Di Desa Passo Kecamatan Kakas.” 11(1): 57-62. 